\title{
Diagnosis of malignant pleural mesothelioma from pleural fluid by Fourier transform-infrared spectroscopy coupled with chemometrics (Erratum)
}

Sherif Abbas

Nihal Simsek Ozek

Salih Emri

Deniz Koksal

Mete Severcan

Feride Severcana 


\title{
Diagnosis of malignant pleural mesothelioma from pleural fluid by Fourier transform-infrared spectroscopy coupled with chemometrics (Erratum)
}

\author{
Sherif Abbas, ${ }^{a, b}$ Nihal Simsek Ozek, ${ }^{a, c, d}$ Salih Emri, ${ }^{e, f}$ Deniz Koksal, ${ }^{e}$ Mete Severcan, ${ }^{g}$ and Feride Severcana ${ }^{\text {,i }}$ \\ aiddle East Technical University, Department of Biological Sciences, Ankara, Turkey \\ ${ }^{\mathrm{b}}$ Ain Shams University, Physics Department, Cairo, Egypt \\ ${ }^{\mathrm{c} A t a t u r k}$ University, Department of Biology, Erzurum, Turkey \\ dAtaturk University, East Anatolian High Technology Research and Application Center (DAYTAM), Erzurum, Turkey \\ eHacettepe University, Department of Chest Diseases, Ankara, Turkey \\ ${ }^{f}$ Altinbas University, Department of Chest Diseases, Faculty of Medicine, Istanbul, Turkey \\ 9Middle East Technical University, Department of Electrical and Electronic Engineering, Ankara, Turkey \\ ${ }^{\mathrm{h}}$ Altinbas University, Department of Biophysics, Faculty of Medicine, Istanbul, Turkey \\ 'Altinbas University, Graduate Program of Biomedical Sciences, Institute of Health Sciences, Istanbul, Turkey
}

[DOI: $10.1117 / 1 . J B O \cdot 23 \cdot 10.109801]$

This article [J. Biomed. Opt. 23(10), 105003(2018)] was originally published online on 13 October 2018 with an error on page 10 , which misstated the average accuracy of test sample classification.

The original sentence states, "Cooman's plot of MPM versus LC and MPM versus BPE models demonstrated the correct classification of tested samples from each group with an average of 95.6\% accuracy."

The corrected sentence states, "Cooman's plot of MPM versus LC and MPM versus BPE models demonstrated the correct classification of tested samples from each group with an average of $96.2 \%$ accuracy."

This article was corrected online on 16 October 2018. It appears correctly in print. 